\title{
The Pharmacokinetics of Low-Dose Thalidomide in Japanese Patients with Refractory Multiple Myeloma
}

\author{
Rintaro Kamikawa, ${ }^{a}$ Kazuro Ikawa, ${ }^{*}, b$ Norifumi Morikawa, ${ }^{b}$ Hideki Asaoku, ${ }^{c}$ Koji Iwato, ${ }^{d}$ and \\ Ayako SASAKI ${ }^{e}$ \\ ${ }^{a}$ Department of Pharmacy, Hiroshima Red Cross Hospital and Atomic-bomb Survivors Hospital; ${ }^{c}$ Department of Clinical \\ Laboratory, Hiroshima Red Cross Hospital and Atomic-bomb Survivors Hospital; ${ }^{~}$ Department of Blood Transfusion, \\ Hiroshima Red Cross Hospital and Atomic-bomb Survivors Hospital; 1-9-6 Senda-machi, Naka-ku, Hiroshima 730-8619, \\ Japan: ${ }^{b}$ Department of Clinical Pharmacotherapy, Hiroshima University; 1-2-3 Kasumi, Minami-ku, Hiroshima \\ 734-8551, Japan: and ${ }^{e}$ Department of Internal Medicine, Motonaga Hospital; 8-13 Saijookamachi, Higashihiroshima \\ 739-0016, Japan. Received June 20, 2006; accepted August 28, 2006
}

Thalidomide has been used for the treatment of refractory multiple myeloma, the dosage in Japan is lower than in other countries; however, there is little information on the pharmacokinetics and their relationship with the drug response. The aim of this study was to characterize the pharmacokinetics of low-dose thalidomide in Japanese patients with refractory multiple myeloma, and to examine the relationship between pharmacokinetics and adverse events. On the first and second days, a $100 \mathrm{mg}$ capsule was administered to 8 Japanese patients after breakfast and blood samples were obtained. The plasma concentrations were measured using HPLC and analyzed based on a one-compartment model. If intolerable adverse events were not observed for $14 \mathrm{~d}$, the dose was increased to $200 \mathrm{mg}$. The average apparent volume of distribution $(V d / F)$, apparent total clearance $(C L / F)$ and area under the plasma concentration-time curve from 0 to infinity $\left(A U C_{0-\infty}\right)$, which were $45.3 \mathrm{l}, 5.5 \mathrm{l} / \mathrm{h}$ and $21.7 \mu \mathrm{g} \cdot \mathrm{h} / \mathrm{ml}$, respectively, with smaller $V d / F$ and $C L / F$ and larger $A U C_{0-\infty}$ than in Caucasian populations. This pharmacokinetic difference may explain the dose difference between Japan and other countries. Adverse events were associated with $A U C_{0 \_\infty}$, which was best correlated with plasma concentration at $12 \mathrm{~h}$ after administration. The 12-h time point was suggested to be a capable indicator for "safety-oriented" therapeutic drug monitoring of thalidomide.

Key words thalidomide; pharmacokinetics; multiple myeloma

Thalidomide was first developed as a hypnotic drug in the $1950 \mathrm{~s}$, and was subsequently withdrawn from the market due to its teratogenicity. ${ }^{1)}$ In recent decades, several reports have demonstrated that thalidomide was effective against refractory multiple myeloma. ${ }^{2,3)}$ However, little is known about the pharmacokinetics of thalidomide in patients with multiple myeloma, and the relationship between the pharmacokinetics and the drug response is still unclear. In Japan, thalidomide has been used for the treatment of refractory multiple myeloma with a dose of 100 to $200 \mathrm{mg}$ per day, less than or comparable to $400 \mathrm{mg}$ per day, ${ }^{4,5)}$ while in other countries the dose is generally from 200 to $800 \mathrm{mg}$ per day. ${ }^{6,7)}$ Especially in Japanese patients with multiple myeloma, pharmacokinetic research may be a clue to explain the dose difference and adjust the dose to avoid adverse events. We assessed the pharmacokinetics of low-dose thalidomide in Japanese patients with refractory multiple myeloma, and examined the relationship between the pharmacokinetics and adverse events.

\section{MATERIALS AND METHODS}

Subjects Japanese patients with multiple myeloma were included at Hiroshima Red Cross Hospital and Atomic-bomb Survivors Hospital from June 2003 to April 2005. Written informed consent was obtained from all patients when they were enrolled in this study. The study was approved by the Ethics Committee of Hiroshima Red Cross Hospital and Atomic-bomb Survivors Hospital, and conducted in compliance with Good Clinical Practice and the Declaration of Helsinki.
Study Schedule Thalidomide capsule (Sauramide $100 \mathrm{mg}$ ) was purchased from Penn Pharmaceutical Services Limited (Tredegar, U.K.). One hundred milligrams once daily were administered as the initial dose. On the first and second days, $100 \mathrm{mg}$ thalidomide was taken orally after breakfast, and venous blood samples were obtained at 1, 2, 4, $6,8,12,24 \mathrm{~h}$ after administration. On the following days, thalidomide was taken at night as usual. If intolerable adverse events were not observed for $14 \mathrm{~d}$, the dose was increased to $200 \mathrm{mg}$ once daily. Adverse events were graded according to the National Cancer Institute-Common Toxicity Criteria, Version 2.0. For Grade 1 and Grade 2, symptomatic treatment was provided; if adverse events were not improved and patients were not tolerable, the dose was halved, administered on alternate days, or discontinued. When Grade 3 effects, except hematological toxicity, were observed, the drug was discontinued.

Determination of Plasma Thalidomide Concentration The plasma concentration of thalidomide was determined by high-performance liquid chromatography with modification of the method of Zhou et al. ${ }^{8)}$

Pharmacokinetic Analysis Pharmacokinetic analysis was performed using a nonlinear least squares program MULTI. ${ }^{9)}$ Data sets were fitted by one-compartment model with first order absorption and elimination. Pharmacokinetic parameter was set separately for each administration to assess the intra-individual variability.

Statistical Analysis Data sets of adverse events and the area under the plasma concentration-time curve from 0 to infinity $\left(A U C_{0-\infty}\right)$ after the first and second $100 \mathrm{mg}$ administration were divided into two groups by the cutoff $A U C_{0-\infty}$ 


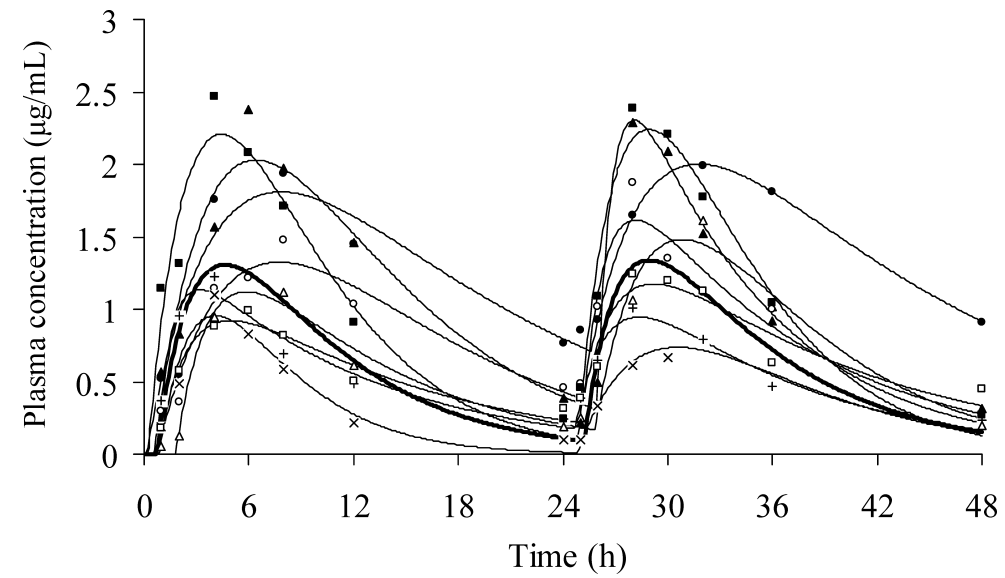

Fig. 1. The Plasma Concentration-Time Plot after the First and Second $100 \mathrm{mg}$ Thalidomide Administration ( $n=8)$

Plain line, simulation curve in each subject (patient A, $\mathbf{O}$; B, $\mathbf{\Delta}$; C, $\mathbf{\square}$; D, O; E, $\triangle$; F, $\square ; \mathrm{G},+; \mathrm{H}, \times$ ) by compartment model; Bald line, simulation curve using the mean values of pharmacokinetic parameters.

value (generated by $1 \mu \mathrm{g} \cdot \mathrm{h} / \mathrm{ml}$ from 8 to $43 \mu \mathrm{g} \cdot \mathrm{h} / \mathrm{ml}$ ) in receiver operating characteristic (ROC) curve analysis. At each cutoff $A U C_{0-\infty}$ value, sensitivity, specificity, and positive and negative likelihood ratios were calculated. The cutoff $A U C_{0 \_}$value for adverse events was determined by drawing the ROC curve. Correlations between $A U C_{0-_{\infty}}$ and plasma concentration at each time point $(1,2,4,6,8,12,24 \mathrm{~h})$ after the first and second administration were evaluated by simple linear regression analysis.

\section{RESULTS}

Demographics Eight patients were six females and two

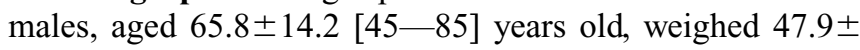
9.6 [38.1-67.9] kilograms (mean \pm S.D. [minimum-maximum]).

Pharmacokinetics The plasma concentration-time profiles after the first and second administration at a dose of $100 \mathrm{mg}$ were well fitted to the simulation curves (Fig. 1). The pharmacokinetic parameters are summarized in Table 1. Each parameter was not significantly different between the first and second administration.

Dosage and Adverse Events The dosage and adverse events were classified into three patterns (Table 2). In the first pattern, patients $\mathrm{A}$ and $\mathrm{C}$ suffered Grade 2 adverse events and patient $\mathrm{B}$ complained leg edema at a dose of $100 \mathrm{mg}$, and the dosing rate was reduced and discontinued within 4 weeks. In the second pattern, with the dose increased to $200 \mathrm{mg}$, patient D suffered Grade 3 adverse events and the drug was discontinued. Patients $\mathrm{E}$ and $\mathrm{F}$ complained various Grade 1 adverse events, then the dosing rate was decreased, and was finally discontinued within 12 weeks. In the third pattern, adverse events did not occur at a dose of $200 \mathrm{mg}$. Patient $\mathrm{H}$ was maintained at $200 \mathrm{mg}$ for more than a year, although patient $\mathrm{G}$ withdrew informed consent and discontinued the treatment on Day 44.

Relationship between Adverse Events, $A U C$ and Plasma Concentrations Analyzing the data sets of adverse events (presence, patients A, B and C; absence, the other patients) and $A U C_{0-\infty}$ after the first and second $100 \mathrm{mg}$ administration, the ROC curve indicated that adverse events were associated with the $A U C_{0-\infty}$ of thalidomide: the cutoff
Table 1. Pharmacokinetic Parameters of Thalidomide $(100 \mathrm{mg})$ after the First and Second Oral Administration

\begin{tabular}{lcc}
\hline \hline \multicolumn{1}{c}{ Parameter } & 1st & 2nd \\
\hline$V d / F(\mathrm{l})$ & $42.2 \pm 23.5$ & $47.1 \pm 21.4$ \\
$C L / F(1 / \mathrm{h})$ & $5.54 \pm 3.05$ & $5.44 \pm 2.07$ \\
$T_{\mathrm{lag}}(\mathrm{h})$ & $0.73 \pm 0.51$ & $1.22 \pm 0.50$ \\
$K_{\mathrm{a}}(1 / \mathrm{h})$ & $0.40 \pm 0.32$ & $0.46 \pm 0.32$ \\
$K_{\mathrm{e}}(1 / \mathrm{h})$ & $0.15 \pm 0.08$ & $0.13 \pm 0.06$ \\
$T_{1 / 2}(\mathrm{~h})$ & $5.71 \pm 2.58$ & $6.32 \pm 2.76$ \\
$C_{\max }(\mu \mathrm{g} / \mathrm{ml})$ & $1.44 \pm 0.50$ & $1.39 \pm 0.54$ \\
$T_{\max }(\mathrm{h})$ & $5.55 \pm 1.70$ & $5.78 \pm 1.61$ \\
$A U C_{0-\infty}(\mu \mathrm{g} \cdot \mathrm{h} / \mathrm{ml})$ & $22.6 \pm 10.9$ & $21.0 \pm 8.58$ \\
\hline
\end{tabular}

Mean \pm S.D. $(n=8)$. $V d$, volume of distribution; $F$, fraction of absorbed dose (bioavailability); $C L$, total clearance; $T_{\mathrm{lag}}$, absorption lag time; $K_{\mathrm{a}}$, absorption rate constant; $K_{\mathrm{e}}$, elimination rate constant; $T_{1 / 2}$, elimination half-life; $C_{\max }$, maximum plasma concentration; $T_{\max }$, time to $C_{\max } ; A U \mathrm{C}_{0-\infty}$, area under the plasma concentration-time curve from 0 to infinity.

$A U C_{0-\infty}$ value for adverse events was 23 and $24 \mu \mathrm{g} \cdot \mathrm{h} / \mathrm{ml}$, and the sensitivity, 1-specificity, positive likelihood ratio and negative likelihood ratio were $0.83,0.1,8.3$ and 0.19 , respectively (Fig. 2).

The best correlation was observed between $A U C_{0-\infty}$ and plasma concentration at $12 \mathrm{~h}\left(C_{12}\right)$ after both the first and second administration alike, though the mean intra-individual variation $\left(\left[C_{12(2 \mathrm{nd})}-C_{12(1 \mathrm{st})}\right] / C_{12(1 \mathrm{st})} \times 100\right)$ was $30.6 \%$. With this correlation, $23-24 \mu \mathrm{g} \cdot \mathrm{h} / \mathrm{ml}$ of $A U C_{0-\infty}$ was estimated to be relevant to $0.85-0.89$ and $1.03-1.09 \mu \mathrm{g} / \mathrm{ml}$ of $C_{12}$ after the first and second administration, respectively (Fig. 3).

\section{DISCUSSION}

This study was a full sampling design to examine the pharmacokinetics precisely in Japanese patients with multiple myeloma. The mean values of the volume of distribution including the fraction of absorbed dose $(V d / F)$, the total clearance including the fraction of absorbed dose $(C L / F)$ and the elimination half-life $\left(T_{1 / 2}\right)$ were $42.2-47.11,5.44-5.54 \mathrm{l} / \mathrm{h}$ and $5.71-6.32 \mathrm{~h}$, respectively (Table 1 ), and $V d / F$ and $C L / F$ were smaller than those reported previously: Teo et al. ${ }^{10)}$ found that the averages of $V d / F, C L / F$ and $T_{1 / 2}$ were 94.01 , $11.1 \mathrm{l} / \mathrm{h}$ and $5.75 \mathrm{~h}$, respectively, after $200 \mathrm{mg}$ dosing to healthy male subjects. Piscitelli et al. ${ }^{11)}$ demonstrated that the 
Table 2. The $A U \mathrm{C}_{0-\infty}$ after theFirst and Second $100 \mathrm{mg}$ Thalidomide Administration, and Adverse Events at Doses of 100 or $200 \mathrm{mg}$ Thalidomide

\begin{tabular}{|c|c|c|c|c|c|c|c|c|}
\hline Patient & A & $\mathrm{B}$ & $\mathrm{C}$ & $\mathrm{D}$ & $\mathrm{E}$ & $\mathrm{F}$ & G & $\mathrm{H}$ \\
\hline$A U C_{0-\infty}(\mu \mathrm{g} \cdot \mathrm{h} / \mathrm{ml})$ & 42.43 & 32.12 & 25.23 & 25.15 & 16.10 & 16.09 & 15.64 & 8.28 \\
\hline after $1 \mathrm{st}$ and $2 \mathrm{nd} 100 \mathrm{mg}$ & 38.98 & 22.13 & 24.79 & 19.51 & 19.15 & 19.62 & 12.15 & 11.46 \\
\hline \multicolumn{9}{|l|}{ Adverse effect } \\
\hline Dose (mg) & 100 & 100 & 100 & 200 & 200 & 200 & 200 & 200 \\
\hline \multicolumn{9}{|l|}{ [Grade 3] } \\
\hline Acute bronchitis & & & & 0 & & & & \\
\hline \multicolumn{9}{|l|}{ [Grade 2] } \\
\hline Anosmia & O & & & & & & & \\
\hline Taste disorder & & & $\bigcirc$ & & & & & \\
\hline \multicolumn{9}{|l|}{ [Grade 1] } \\
\hline Somnolence & & & $\bigcirc$ & & $\bigcirc$ & $\bigcirc$ & & \\
\hline Stagger & & & $\bigcirc$ & & $\bigcirc$ & $\bigcirc$ & & \\
\hline Constipation & $\bigcirc$ & & & & O & & & \\
\hline Fatigue or asthenia & $\bigcirc$ & & $\bigcirc$ & & & & & \\
\hline Chill & & & $\bigcirc$ & & & & & \\
\hline Dizziness & & & & & & $\bigcirc$ & & \\
\hline Heavy stomach & & & & & $\bigcirc$ & & & \\
\hline Leg edema & & $\bigcirc$ & & & & & & \\
\hline Oral aphtha & & & $\bigcirc$ & & & & & \\
\hline Tachypnea & & & & & $\bigcirc$ & & & \\
\hline
\end{tabular}

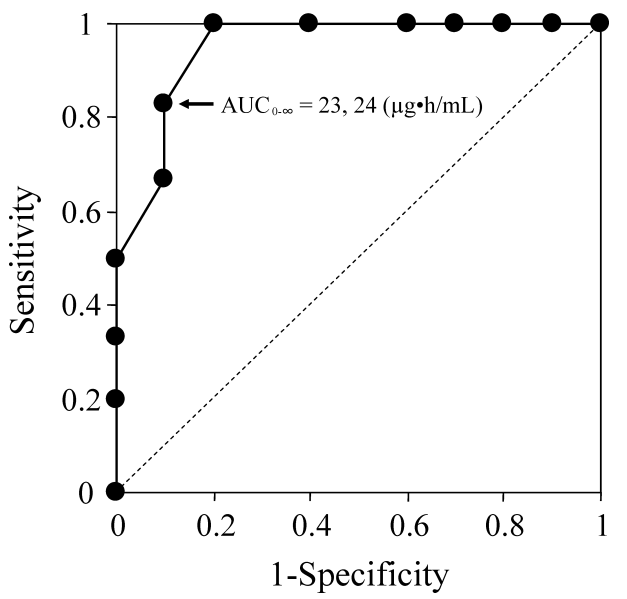

Fig. 2. Receiver Operating Characteristic (ROC) Curve of $A U C_{0-\infty}$ and Adverse Events of Thalidomide

Black arrow indicates the cutoff point $\left(A U C_{0-\infty}=23,24 \mu \mathrm{g} \cdot \mathrm{h} / \mathrm{ml}\right)$.

averages of $V d / F, C L / F$ and $T_{1 / 2}$ were $87.81,9.21 / \mathrm{h}$ and 6.5 $\mathrm{h}$, respectively, after $100 \mathrm{mg}$ dosing to human immunodeficiency virus-infected patients. Thalidomide pharmacokinetics are evaluated to be similar between healthy and patient populations, ${ }^{12)}$ and we speculated that the smaller $V d / F$ and $C L / F$ may result from differences other than diseases, for example, lower body weight or higher bioavailability in Japanese patients. Consequently, $A U C_{0-\infty}$ was $22.6 \pm 10.9$ and $21.0 \pm 8.58 \mu \mathrm{g} \cdot \mathrm{h} / \mathrm{ml}$ after the first and second $100 \mathrm{mg}$ administration, respectively (Table 1). This was comparable to $20.9 \pm 6.7 \mu \mathrm{g} \cdot \mathrm{h} / \mathrm{ml}$ after $200 \mathrm{mg}$ dosing to five New Zealand patients with refractory multiple myeloma. ${ }^{13)}$ We considered that this pharmacokinetic difference may explain the dose difference for the treatment of refractory multiple myeloma.

ROC curve analysis ${ }^{14,15)}$ was performed to examine the relationship between adverse events and $A U C_{0-\infty}$. ROC curve is a graphical plot of the sensitivity versus 1 -specificity for a binary classifier system as its discrimination threshold is varied. The best possible prediction method would yield a graph

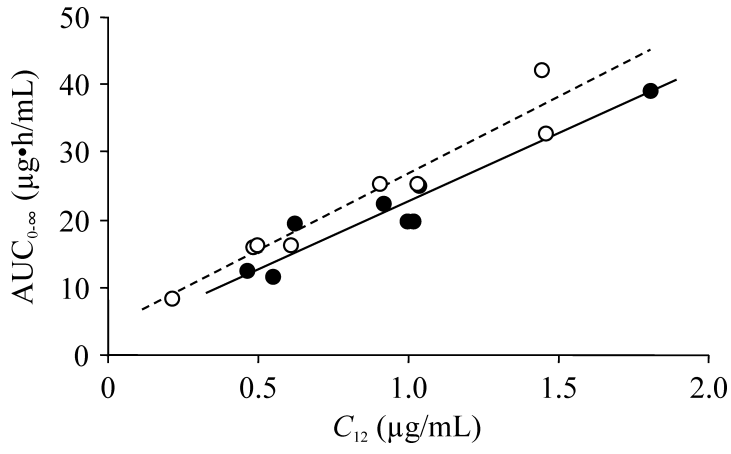

Fig. 3. The Correlation of Plasma Concentration at $12 \mathrm{~h}\left(C_{12}\right)$ with $A U C_{0-\infty}$ after the First ( $\bigcirc$ and Dashed Line, $Y=22.77 X+3.66, r=0.96$ ) and Second ( and Solid Line, $Y=19.44 X+2.89, r=0.96) 100 \mathrm{mg}$ Thalidomide Administration

that is a point in the upper left corner of the ROC space. As shown in Fig. 2, $A U C_{0-\infty}$ was associated with adverse events of thalidomide and the cutoff $A U C_{0-\infty}$ value for adverse events was $23-24 \mu \mathrm{g} \cdot \mathrm{h} / \mathrm{ml}$. Although we did not evaluate $A U C_{0-\infty}$ at a dose of $200 \mathrm{mg}$, we expect that $A U C_{0-\infty}$ at a dose of $200 \mathrm{mg}$ may be double that at a dose of $100 \mathrm{mg}$, taking into consideration that $A U C_{0-\infty}$ increased proportionally with doses from 50 to $400 \mathrm{mg}$ in healthy male subjects. ${ }^{16}$ ) Thus, we speculated that, at $200 \mathrm{mg}$ dosing, patients D, E and F suffered adverse events because their $A U C_{0-\infty}$ was above $23-24 \mu \mathrm{g} \cdot \mathrm{h} / \mathrm{ml}$, while patients $\mathrm{G}$ and $\mathrm{H}$ did not suffer adverse events because their $A U C_{0-\infty}$ was approximately equal or below the cutoff value (Table 2).

Previous researches ${ }^{4,17)}$ examined the relationship between the plasma concentrations of thalidomide and the drug response in Japanese patients with multiple myeloma, and demonstrated that thalidomide-related toxicity except neutropenia occurred more frequently with higher plasma levels $\left(C_{12}>2.0 \mu \mathrm{g} / \mathrm{ml}\right)$. The present study also suggested that it was important to monitor $C_{12}$ for safety reason, however, its cutoff value was lower $(1 \mu \mathrm{g} / \mathrm{ml})$. We considered this discrepancy was because our analyses placed the highest prior- 
ity on avoiding adverse events to continue the treatment.

As well as previous studies, ${ }^{10,16)}$ this study was conducted in daytime although thalidomide is usually administered before bedtime. In the approved protocol, we gave priority to frequent full sampling on the initial two days, and were unable to obtain samples another time due to reducing the burden of excessive sampling for patients. Gastric emptying rate, intestinal blood flow rate and peristaltic activity could differ between day and night, we did not examine the influence of administration time on the pharmacokinetics of thalidomide. Further pharmacokinetic research to collect the steady-state plasma samples after nighttime administration, especially $C_{12}$ in the morning, is needed to confirm whether $1 \mu \mathrm{g} / \mathrm{ml}$ is appropriate as a target value for "safety-oriented" therapeutic drug monitoring of thalidomide to avoid adverse events and continue the treatment.

\section{REFERENCES}

1) Eriksson T., Bjorkman S., Hoglund P., Eur. J. Clin. Pharmacol., 57, $365-376(2001)$.

2) Juliusson G., Celsing F., Turesson I., Lenhoff S., Adriansson M., Malm C., Br. J. Haematol., 109, 89—96 (2000).

3) Tosi P., Zamagni E., Cellini C., Ronconi S., Patriarca F., Ballerini F., Musto P., Di Raimondo F., Ledda A., Lauria F., Masini L., Gobbi M., Vacca A., Ria R., Cangini D., Tura S., Baccarani M., Cavo M., Haematologica, 87, 408-414 (2002).

4) Kakimoto T., Hattori Y., Okamoto S., Sato N., Kamata T., Yamaguchi M., Morita K., Yamada T., Takayama N., Uchida H., Shimada N.,
Tanigawara Y., Ikeda Y., Jpn. J. Cancer Res., 93, 1029-1036 (2002).

5) Murakami H., Handa H., Imai K., Kanakura Y., Kosaka M., Sawamura M., Shimazaki C., Suzuki K., Ishii A., Takagi T., Taniwaki M., Togawa A., Hata H., Wakayama T., Takatsuki K., Rinsho Ketsueki, 45, 468472 (2004).

6) Barlogie B., Desikan R., Eddlemon P., Spencer T., Zeldis J., Munshi N., Badros A., Zangari M., Anaissie E., Epstein J., Shaughnessy J., Ayers D., Spoon D., Tricot G., Blood, 98, 492- 494 (2001).

7) Raza A., Meyer P., Dutt D., Zorat F., Lisak L., Nascimben F., du Randt M., Kaspar C., Goldberg C., Loew J., Dar S., Gezer S., Venugopal P., Zeldis J., Blood, 98, 958-965 (2001).

8) Zhou S., Li Y., Kestell P., Paxton J. W., J. Chromatogr. B Analyt. Technol. Biomed. Life Sci., 785, 165-173 (2003).

9) Yamaoka K., Tanigawara Y., Nakagawa T., Uno T., J. PharmacobioDyn., 4, 879-885 (1981).

10) Teo S. K., Colburn W. A., Thomas S. D., J. Clin. Pharmacol., 39, 1162-1168 (1999).

11) Piscitelli S. C., Figg W. D., Hahn B., Kelly G., Thomas S., Walker R. E., Antimicrob. Agents Chemother, 41, 2797-2799 (1997).

12) Teo S. K., Colburn W. A., Tracewell W. G., Kook K. A., Stirling D. I., Jaworsky M. S., Scheffler M. A., Thomas S. D., Laskin O. L., Clin. Pharmacokinet., 43, 311-327 (2004).

13) Chung F., Lu J., Palmer B. D., Kestell P., Browett P., Baguley B. C., Tingle M., Ching L. M., Clin. Cancer Res., 10, 5949—5956 (2004).

14) Tredger J. M., Brown N. W., Adams J., Gonde C. E., Dhawan A., Rela M., Heaton N., Liver Transpl., 10, 492-502 (2004).

15) Pawinski T., Durlik M., Szlaska I., Urbanowicz A., Ostrowska J., Gralak B., Majchrzak J., Transplant. Proc., 38, 86-89 (2006).

16) Teo S. K., Scheffler M. R., Kook K. A., Tracewell W. G., Colburn W. A., Stirling D. I., Thomas S. D., J. Clin. Pharmacol., 41, 662-667 (2001).

17) Hattori Y., Iguchi T., Congenit. Anom., 44, 125-136 (2004). 